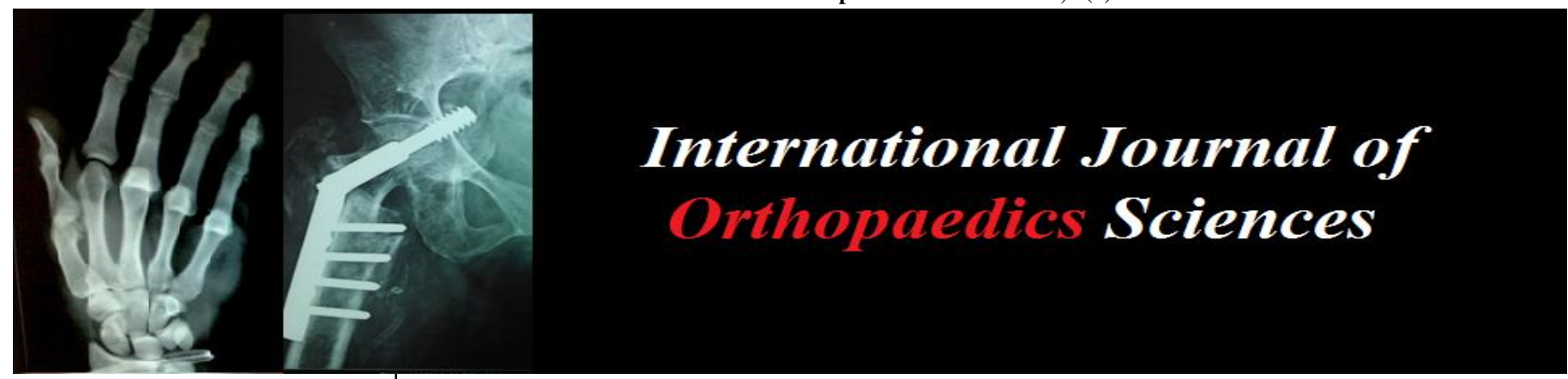

ISSN: $2395-1958$

IJOS 2018; 4(4): 164-168

(C) 2018 IJOS

www.orthopaper.com

Received: 29-08-2018

Accepted: 30-09-2018

Dr. Sudhir KAM Shandilya Professor and HOD, Dept of Orthopaedics, ASRAM Medical College, Malakapuram, Eluru, West Godavari District, Andhra Pradesh, India

Dr. RM Mallikarjun Reddy Professor, Dept of Orthopaedics ASRAM Medical College,

Malakapuram, Eluru

West Godavari District,

Andhra Pradesh, India

Dr. Sravan Chandar Dutta Assistant Professor, Dept of Orthopaedics ASRAM Medical College, Malakapuram, Eluru

West Godavari District,

Andhra Pradesh, India

Dr. Gontu Venkat Satya Rahul Reddy

Post Graduate Student, Dept of Orthopaedics ASRAM Medical

College, Malakapuram, Eluru,

Andhra Pradesh, India

Dr. Srinivas Rudra

Post Graduate Student, Dept of Orthopaedics ASRAM Medical College, Malakapuram, Eluru,

Andhra Pradesh, India

Dr. Gandham Satya Avinash Post Graduate Student, Dept of Orthopaedics ASRAM Medical College, Malakapuram, Eluru, Andhra Pradesh, India
Correspondence

Dr. Sravan Chandar Dutta Assistant Professor, Dept of Orthopaedics ASRAM Medical College, Malakapuram, Eluru West Godavari District, Andhra Pradesh, India

\section{Dynamic compression plating is the gold standard for the treatment of fracture both bones of forearm: A series of 30 cases}

\author{
Dr. Sudhir KAM Shandilya, Dr. RM Mallikarjun Reddy, Dr. Sravan \\ Chandar Dutta, Dr. Gontu Venkat Satya Rahul Reddy, Dr. Srinivas \\ Rudra and Dr. Gandham Satya Avinash
}

DOI: https://doi.org/10.22271/ortho.2018.v4.i4c.29

\section{Abstract}

The forearm movements are important in activities of daily living. The proximal and distal radioulnar joints, allows pronation and supination required to perform multi axial movements.

Fractures of forearm bones have become more common due to increased high speed vehicles, industrialization, sports and mechanical farming. Inadequate treatment of those fractures may result in severe loss of function. Good anatomical reduction and internal fixation is necessary to restore function. The aim of present study was to assess the functional outcome of ORIF of fracture both bones forearm using Dynamic Compression Plate.

Material and methods: Thirty patients (18-50 years age) of with diaphyseal fractures of both bones forearm from November 2016 to October 2018 were treated by ORIF using 3.5mm DCP by standard techniques and results were evaluated based on "Anderson et al." scoring system.

Results: We had $23(76.66 \%)$ excellent results, 4 (16.66) satisfactory results and $1(3.33 \%)$ unsatisfactory result and $1(3.33 \%)$ failure. The failure was due to ulnar nonunion which was later treated by ORIF with bone graft.

Conclusion: With use of DCP for ORIF of both bones forearm fractures, we can achieve all four AO principles of internal fixation (1) Anatomical reduction, (2) Preservation of vascularity, (3) Mechanically stable fixation, (4) Rapid mobilization of joints. Thus, DCP is a good implant for treating displaced fractures of the forearm bones.

Keywords: Both bones forearm fractures, ORIF, DCP, dynamic compression plating

\section{Introduction}

The forearm, being a component of upper limb serves important movements that are important in activities of daily living. The forearm, in combination with the proximal and distal radioulnar joints, allows pronation and supination which in turn helps hand, to perform multi axial movements.

With mechanized farming in India and industrialization, fractures of forearm bones have become more common. Fracture of the forearm bones may result in severe loss of function unless adequately treated. Hence good anatomical reduction and internal fixation of these fractures is necessary to restore function ${ }^{[4]}$.

Closed reduction which was employed in earlier days yielded unsatisfactory results from either nonunion or loss of motion. Also, there are complex forces acting on the forearm bone that makes reduction and its maintenance of displaced fracture fragments difficult ${ }^{[5]}$.

Union may be achieved with any of the methods available however severe loss of function may be the end result unless adequately treated with proper technique and implants. With the development of compression plate osteosynthesis which provides a good treatment option and predictable outcome, there is an important change in the treatment of forearm fractures ${ }^{[8]}$ This method helps in perfect reduction of fracture fragments in anatomical position by rigid fixation and early mobilization of the hand can be achieved. 
Bagby and Denham15 were the first to describe Dynamic compression plate and more recently developed by the AO school has an intrinsic compression device making extensive dissection unnecessary. The plate depends upon the obliquity of cylindrical screw-holes for compression which is produced as the screws are driven home. The most effective method of producing rigid internal fixation is using compression plates developed by the AO School in Switzerland.

\section{Aim}

The aim of present study was to assess the functional outcome of open reduction and internal fixation of fracture both bones forearm with plate osteosynthesis using Dynamic Compression Plate.

\section{Objectives}

To assess functional outcome using Anderson et al.. scoring system.

To study fracture healing and union rate by using serial radiographs.

To prevent angulations and rotational deformity.

To mobilize the forearm as early as possible.

To study age and sex distribution of the patients with fracture of both bone forearm in adults

To study complications of surgery if any depending upon the level of fracture.

\section{Material and methods}

A prospective study of thirty patients in the age group of 1850 years with diaphyseal fractures of both bones forearm admitted during the period of November 2016 to October 2018, meeting the inclusion criterion are the subjects for the present study.

\section{Inclusion Criteria}

Patients with closed diaphyseal fractures of both bones of forearm.

Patients above the age of 18 years and below $60 \mathrm{yrs}$.

Patients fit for surgery.

\section{Exclusion Criteria}

Compound fractures of forearm bones

Patients not willing for surgery

Patients medically unfit for surgery

Pathological fractures

Age below 18 years and above 60

Osteoporotic fracture

All patients admitted with both bone fractures of the forearm, a careful history was elicited from the patient and / or attendants to reveal the mechanism of injury and the severity of trauma.

The patients were then assessed clinically to evaluate their general condition and the local injury. It was done in accordance to Acute Trauma Life Support protocol. Vital parameters were recorded.

\section{Imaging}

Radiographs of the forearm both wrist and elbow joints., anteroposterior and lateral views, were obtained

Proximal radius was approached by dorsal Thompson incision and volar Henry approach was used for middle and distal radius. Ulna was approached by direct incision on subcutaneous border. A narrow 3.5mm DCP was used and a minimum of 6 cortices were engaged with screw fixation in each fragment.

\section{Operative Procedure}

Type of anesthesia: General anesthesia was used in 14 cases and brachial block in 16 cases.

Post-operative care: Posterior slab was continued or arm pouch was given depending upon the requirement.

Limb is elevated and active movement of the fingers is encouraged. Suction drain was removed after 48 hours and Wound was inspected. Check X ray AP and Lateral view was taken at that time.

Antibiotics and analgesics were continued till the time of suture removal which was done on 10-12 postoperative day. On discharge patient was advised physiotherapy of shoulder, elbow, wrist and finger movements. They were told not to lift heavy weight or exert the affected forearm till there is radiological evidence of fracture union.

\section{Follow-up}

The patients were followed regularly at monthly interval for first three months then every three months depending upon the outcome. The patients were evaluated based on "Anderson et al."1scoring system. Elbow movements and wrist movements were noted, and the union was assessed radio logically. The fracture is 'said to be united when there was presence of periosteal callus bridging the fracture site and trabeculation extending across the fracture line.

\section{Results}

In this study 30 patients with displaced forearm fractures were treated by open reduction and internal fixation with $3.5 \mathrm{~mm}$ dynamic compression plate (DCP).

Age distribution: The age of these patients ranged from 1860 years and an average age of 38years.

\begin{tabular}{|c|c|c|}
\hline Age & Number of patients & Percentage \\
\hline $19-30$ & 10 & $33.33 \%$ \\
\hline $31-40$ & 8 & $26.67 \%$ \\
\hline $41-50$ & 5 & $16.67 \%$ \\
\hline $51-60$ & 7 & $23.33 \%$ \\
\hline Total & 30 & $100.00 \%$ \\
\hline
\end{tabular}

\section{Sex Distribution}

Out of 30 patients, 22 patients $(73.33 \%)$ were males and 8 patients $(26.66 \%)$ were females showing male preponderance because of more males are working in fields, travelling, factories, and sports.

\begin{tabular}{|c|c|c|}
\hline Sex & Number of Patients & Percentage \\
\hline Male & 22 & $73.33 \%$ \\
\hline Female & 8 & $26.66 \%$ \\
\hline Total & 30 & $100.00 \%$ \\
\hline
\end{tabular}

There were $15(50 \%)$ patients with right forearm fracture and 15 patients $(50 \%)$ with left forearm fracture.

\begin{tabular}{|c|c|c|}
\hline Side affected & Number of Patients & Percentage \\
\hline Right forearm & 15 & $50.00 \%$ \\
\hline Left forearm & 15 & $50.00 \%$ \\
\hline Total & 30 & $100.00 \%$ \\
\hline
\end{tabular}

\section{Mode of Injury}

In our study, there were $11(36.66 \%)$ patients with road traffic accidents, $15(50 \%)$ patients with fall, and $4(13.33 \%)$ patients with assault. 


\begin{tabular}{|c|c|c|}
\hline Mode of injury & Number of patients & Percentage \\
\hline RTA & 11 & $36.66 \%$ \\
\hline Fall on out stretched hand & 15 & $50.00 \%$ \\
\hline Assault & 4 & $13.33 \%$ \\
\hline Total & 30 & $100.00 \%$ \\
\hline
\end{tabular}

Fracture characteristics

Clinical: All the fractures were closed injuries.

Level of fracture

\begin{tabular}{|c|c|c|}
\hline Level of fracture & Number of Patients & Percentage \\
\hline Proximal third & 8 & $26.66 \%$ \\
\hline Middle third & 17 & $56.33 \%$ \\
\hline Distal third & 5 & $16.66 \%$ \\
\hline Total & 30 & $100.00 \%$ \\
\hline
\end{tabular}

Majority of the fractures were seen in the mid diaphysis of both bones of forearm. Seventeen $(56.33 \%)$ patients had mid diaphyseal fractures, eight $(26.66 \%)$ had proximal third fractures and five $(16.66 \%)$ patients had lower third fracture of both bones of forearm.

\section{Type of the fracture}

As we had included diaphyseal fractures of both bones, in our study, in total we had total of 30 radius shaft fractures and 30 ulna fractures.

Among 30 radius fractures, $7(23.33 \%)$ were Transverse and $15(50 \%)$ were short oblique type and $8(26.66 \%)$ were comminuted variety. Among 30 ulna fractures, 3(66.66\%) were Transverse and 19 were short oblique type and 8 $(33.33 \%)$ were comminuted variety.

\begin{tabular}{|c|c|c|c|c|}
\hline Type of fracture & Radius & Percentage & Ulna & \% \\
\hline Transverse & 7 & $23.33 \%$ & 3 & $10 \%$ \\
\hline Short oblique & 15 & $50.00 \%$ & 19 & $63.33 \%$ \\
\hline Comminuted & 8 & $26.66 \%$ & 8 & $26.66 \%$ \\
\hline Total & 30 & $100.00 \%$ & 30 & $100 \%$ \\
\hline
\end{tabular}

\section{Associated injuries}

5 patients $(16.66 \%)$ had associated injuries as shown in following table.

\begin{tabular}{|c|c|c|}
\hline Associated injuries & $\begin{array}{c}\text { Number } \\
\text { of Cases }\end{array}$ & Percentage \\
\hline Ipsilateral humerus shaft and scapula fracture & 1 & $3.33 \%$ \\
\hline Fracture of the shaft of femur & 1 & $3.33 \%$ \\
\hline Metacarpal fractures & 2 & $6.66 \%$ \\
\hline Head injury & 1 & $3.33 \%$ \\
\hline Total & 5 & $16.66 \%$ \\
\hline
\end{tabular}

\section{Statistics of surgery}

16 of the 30 cases were operated under general anesthesia and in other 14 patients brachial block was used. Of 30 radius shaft fractures, dorsal Thompson approach for radius was used in 25 patients and volar Henry's approach for radius was used in 5 patients. Ulna was approached subcutaneously. Follow-up ranged from 6 months to 22 months.

\section{Average duration for radiological union}

The fracture was considered as united when there were no subjective complaints and radiologically when the fracture line was not seen. Arbitrarily, those radial and ulnar fractures which healed in less than 6 months were classified as united; those which required more than 6 months to unite and had no additional operative procedure were classified as delayed union; and those which failed to unite eve after 6 months without another operative procedure were classified as nonunion.

\begin{tabular}{|c|c|}
\hline Bone involved & Duration for union \\
\hline Both Radius \& ulna & 12.3 weeks \\
\hline Only radius & 10.3 weeks \\
\hline Only Ulna & 11.6 weeks \\
\hline
\end{tabular}

$28(93.33 \%)$ patients had sound union in less than 6 months, 1 $(3.33 \%)$ patients had delayed union, and 1 patient $(3.33 \%)$ had a nonunion of ulna.

\section{Duration of Fracture Union}

\begin{tabular}{|c|c|c|}
\hline Time of union & Number of patients & Percentage \\
\hline$<6$ months & 28 & $93.33 \%$ \\
\hline 6 months-1year & 1 & $3.33 \%$ \\
\hline Non-union & 1 & $3.33 \%$ \\
\hline Total & 30 & $100.00 \%$ \\
\hline
\end{tabular}

Criteria for evaluation of results: "Anderson" et al. scoring system (1975).

\begin{tabular}{|c|c|c|c|}
\hline Results & Union & $\begin{array}{c}\text { Flexion/Extension } \\
\text { at elbow joint and } \\
\text { wrist }\end{array}$ & $\begin{array}{c}\text { Supination and } \\
\text { pronation of } \\
\text { forearm }\end{array}$ \\
\hline Excellent & Present & $<100$ loss & $<25 \%$ loss \\
\hline Satisfactory & Present & $<200$ loss & $<50 \%$ loss \\
\hline Unsatisfactory & Present & $>200$ loss & $>50 \%$ loss \\
\hline Failure & \multicolumn{2}{|c|}{ Nonunion with or without loss of motion } \\
\hline
\end{tabular}

\section{Results}

Using the Anderson et al. scoring system we had 23 (76.66\%) patients with excellent results, $4(16.66 \%)$ patients with satisfactory results and $1(3.33 \%)$ patient with unsatisfactory result and $1(3.33 \%)$ patient had failure. The failure was due to ulnar nonunion which was later treated by open reduction and internal fixation with bone graft.

\begin{tabular}{|c|c|c|}
\hline Results & Number of Patients & Percentage \\
\hline Excellent & 24 & $80.00 \%$ \\
\hline Satisfactory & 4 & $13.33 \%$ \\
\hline Unsatisfactory & 1 & $3.33 \%$ \\
\hline Failures & 1 & $3.33 \%$ \\
\hline
\end{tabular}

\section{Complications}

We had complications in about $4(13.33 \%)$ patients with the following type.

\begin{tabular}{|c|c|c|}
\hline Complications & No. of cases & Percentage \\
\hline Superficial infection & 2 & $6.66 \%$ \\
\hline Radioulnar synostosis & 0 & 0 \\
\hline Deep infection & 0 & 0 \\
\hline Non-union & 1 & $3.33 \%$ \\
\hline Nerve injury-Posterior interosseous & 1 & $3.33 \%$ \\
\hline Bone shortening & 0 & 0 \\
\hline Total & 4 & $13.33 \%$ \\
\hline
\end{tabular}

\section{Discussion}

The forearm, being a component of upper limb serves important movements that are important in activities of daily living. The forearm, allows pronation and supination which in turn helps hand, to perform multi axial movements.

Fracture of the forearm bones may result in severe loss of function unless adequately treated. Hence good anatomical reduction and internal fixation of these fractures is necessary to restore function ${ }^{[4]}$. 
This study was conducted at our hospital with the aim of knowing the importance of rigid anatomical reduction and fixation of forearm diaphyseal fractures with $3.5 \mathrm{~mm}$ DCP. This in turn was reciprocated on the functional results obtained. Our study had patient number of 30 to obtain a statistically significant result.

We evaluated our results and compared them with those obtained by various other studies. Our analysis is as follows.

\section{Age distribution}

The age of these patients ranged from 18-60 years and an average age of 37 years. Our findings are comparable to the study made by Michael W. Chapman et al. ${ }^{[6]}$. (1989) series which showed average age as 37years. H. Neville Burwell and A.D. Charnley in 1964 witnessed $50 \%$ of the patients between second and third decade and an average of 44.8 years [2]

In 1972, Herbert S. Dodge and Gerald W. Cady found 24 years as the average age in their series ${ }^{[5]}$. Berton R. Moed (1986) found an average age of 22 years ${ }^{[7]}$.

\begin{tabular}{|c|c|c|c|}
\hline Series & $\begin{array}{c}\text { Min. age } \\
\text { (yrs) }\end{array}$ & $\begin{array}{c}\text { Max. age } \\
\text { (yrs) }\end{array}$ & $\begin{array}{c}\text { Average } \\
(\text { yrs })\end{array}$ \\
\hline Michael Chapman6 & 13 & 79 & 37 \\
\hline Moed7 & 14 & 65 & 22 \\
\hline Herbert Dodge5 & 13 & 59 & 24 \\
\hline H.N. Burwell2 & 16 & 57 & 44.8 \\
\hline Present study & 11 & 65 & 38 \\
\hline
\end{tabular}

\section{Sex distribution}

22 male patients $(73.33 \%)$ and 8 female patients $(26.66 \%)$ in our series shows male preponderance comparable to Michael Chapman who noted about $78 \%$ males and $22 \%$ females $^{6}$ and H. Dodge ${ }^{[5]}$ who had $89 \%$ males and $11 \%$ females in their series ${ }^{[12]}$. Talwalkar in his series had $80 \%$ males and $20 \%$ females ${ }^{[13]}$.

\begin{tabular}{|c|c|c|}
\hline Series & Males (\%) & Females (\%) \\
\hline M. Chapman6 & 78 & 22 \\
\hline Talwalkar13 & 80 & 20 \\
\hline H. Dodge5 & 89 & 11 \\
\hline Present study & $73.33 \%$ & $26.66 \%$ \\
\hline
\end{tabular}

\section{Mode of injury}

In our series $36.66 \%$ of cases (11) had road traffic accidents, $50 \%$ (15) had fall and $13.33 \%$ (4) with history of assault. J.G. Grace et al. ${ }^{[14]}$. noted about $29(45 \%)$ patients with automobile or motorcycle accident, $14(22 \%)$, in falls $2(3 \%)$, had gunshot wounds and remainder had other miscellaneous types of injuries. Moed B. R. et al. . accounted $50 \%$ of his cases to road traffic accident, $20 \%$ due to industrial accident, $14 \%$ due to fall, $12 \%$ due to direct blow and $4 \%$ due to gunshot injuries ${ }^{[7]}$.

Smith noted about $45 \%$ of his cases was due to RTA, $36 \%$ were due to fall and $19 \%$ were due to industrial accidents ${ }^{[10]}$.

[13] Talwalkar series had $26.6 \%$ of his cases to road traffic accident, $16.6 \%$ due to industrial accident, $50 \%$ due to fall and $6.6 \%$ due to direct blow. Our series is comparable to ${ }^{[10]}$ Smith series.

\begin{tabular}{|c|c|c|c|c|}
\hline Series & $\begin{array}{c}\text { Accident } \\
(\%)\end{array}$ & $\begin{array}{c}\text { Fall } \\
(\boldsymbol{\%})\end{array}$ & $\begin{array}{c}\text { Direct blow/ } \\
\text { Assault (\%) }\end{array}$ & $\begin{array}{c}\text { Industrial accident/ } \\
\text { fall of heavy object }\end{array}$ \\
\hline Moed $^{[7]}$ & 70 & 14 & 16 & - \\
\hline Grace $^{[14]}$ & 45 & 22 & 33 & - \\
\hline Smith $^{[10]}$ & 45 & 36 & 19 & - \\
\hline $\begin{array}{c}\text { Talwalkar } \\
{[13]}\end{array}$ & 26.6 & 50 & 6.6 & 16.6 \\
\hline $\begin{array}{c}\text { Present } \\
\text { Study }\end{array}$ & $36.66 \%$ & $50.00 \%$ & $13.33 \%$ & - \\
\hline
\end{tabular}

\section{Extremity affected}

We had about $50 \%$ incidence of forearm fractures in right and left extremity, which is also comparable to the previous studies.

M. W. Chapman reported about 55\% incidence of fractures in right extremity ${ }^{[6]}$.

H. N. Burwell and D.A. Charnley ${ }^{2}$ reported about $50 \%$ incidence of fracture in right arm.

\begin{tabular}{|c|c|c|}
\hline Series & Right (\%) & Left (\%) \\
\hline H.N. Burwell ${ }^{[2]}$ & 50 & 50 \\
\hline M.W. Chapman $^{[6]}$ & 55 & 45 \\
\hline Present study & $50.00 \%$ & $50.00 \%$ \\
\hline
\end{tabular}

\section{Fracture anatomy / Type of fracture}

As in our series we had included diaphyseal fractures of both bones, in our study, in total we had total of 30 radius shaft fractures and 30 ulna shaft fractures. Among 30 radii, $7(23.33 \%)$ were Transverse, $15(50 \%)$ were short oblique type and $8(26.66 \%)$ were comminuted variety.

Among 30 ulnas, 3(10\%) were Transverse, 19(63.33\%) were short oblique type and $8(26.66 \%)$ were comminuted variety. M. W. Chapman et al. ${ }^{[6]}$, series noted about $53 \%$ of fractures as comminuted and $47 \%$ were transverse/short oblique on an average we had $65.33 \%$ with Transverse/ short oblique type and $33.66 \%$ were comminuted variety. Our observation in this respect were not comparable to any of the studies available.

\section{Level of fracture}

M. W. Chapman et al. noted about $59 \%$ and $61 \%$ of fractures in middle third of Radius and ulna, $13 \%$ and $21 \%$ in proximal third of radius and ulna and $28 \%$ and $12 \%$ in lower third of radius and ulna respectively ${ }^{[6]}$. A. Sarmiento et al., noted about $84.6 \%$ of fracture both bones were in middle third and $15.4 \%$ of cases had lower third fracture of both bones ${ }^{[3]}$. H.S. Dodge and G.W. Cady documented $71.5 \%$ fracture both bones $\mathrm{n}$ middle third, $21.5 \%$ in distal third and $7 \%$ in proximal third ${ }^{[5]}$. Our study had $56.33 \%$ of fractures in middle third, $26.66 \%$ in proximal third and $16.66 \%$ in lower third, comparable to previous studies.

\section{Time of union}

Anderson's criteria for evaluation of union were considered. In our study we had an average union time of 11.5 weeks. Anderson's et al. showed union time of around 7.4 weeks with range of 5 to 10 weeks, $97 \%$ of the cases united ${ }^{[1]}$. Chapman in a study had $98 \%$ union with range of 6 to 14 weeks union the average union time was 12 weeks ${ }^{[6]}$. Mc Knee study had average union time of 10.7 weeks with range of 5 to 18 weeks. He had $97.3 \%$ union rate.

The present series had average union time of 11.5 weeks with a range of 8 to 16 weeks. Radius united in all cases We had Ulna union in $96.6 \%$ of cases. The results of our present studies are comparable to the all previous studies.

\section{Functional results}

The range of motion was determined and Anderson et al., scoring system was used as a measure for the functional outcome ${ }^{[1]}$.

Chapman et al. reported 36 cases (86\%) as excellent, 3 satisfactory (7\%), 1 unsatisfactory $(2 \%)$ and 2 failure $(5 \%)^{[6]}$. Anderson et al. ${ }^{[1]}$ reported about $54(50.9 \%)$ cases as excellent, 37 (34.9\%) satisfactory, $12(11.3 \%)$ unsatisfactory and $2(2.9 \%)$ failure ${ }^{[1]}$.

In our series we had $24(80 \%)$ cases with excellent results, 4 
$(13.66 \%)$ were satisfactory and 1 (3.33\%) case of unsatisfactory result and $1(3.33 \%)$ case of failure due to ulnar nonunion. Thus, in our series had $93.33 \%$ of excellent and satisfactory results, $3.33 \%$ unsatisfactory results and $3.33(\%)$ failures which is comparable to the previous studies. Unsatisfactory result was seen in a male patient with comminuted fracture.

\section{Complications}

In our series we had 2 cases of superficial infection. The wound was debrided, pus sent for culture. They resolved with appropriate antibiotics. In one case of proximal radius which was approached through dorsal Henry's approach, patient had posterior interosseous nerve palsy after surgery. Conservative treatment resolved the nerve palsy within 2.5 months. Another case developed nonunion of ulna fracture which was treated with additional bone graft.

\section{Duration of Follow Up}

Anderson et al. ${ }^{[1]}$ had a follow up from 4 month to 9 years with an average of 3 years. In his series, Moed7 followed patients from 12 months to 9 years with an average of 3 years. Chapman series6 had follow-up which ranged from 6 months to 48 months with average of 12 months.

We had a follow up which ranged from 6 months to 22 months with an average mean of 12 months, which is comparable to Chapman series.

\section{Conclusion}

The AO principles of internal fixation namely (1) Anatomical reduction (2) Preservation of vascularity, (3) Mechanically stable fixation, (4) Rapid mobilization of joints in proximity, can be achieved with compression plating system. With rigid/anatomical internal fixation, dynamic compression plate is a good fixation for displaced fractures of the forearm bones. Adherence to AO principles, strict asepsis, proper postoperative rehabilitation and patient education are more important to obtain excellent results. Also, external immobilization was not necessary in intelligent and cooperative patients.

\section{References}

1. Anderson LD, Sisk D, Tooms RE, Park WI. Compression plate fixation in acute diaphyseal fractures of the radius and ulna J. Bone Joint Surg. Am. 1975; 57: 287.

2. Burwell HN, Charnley DA. Treatment of Forearm fractures in adults with particular reference to plate fixation, J. Bone \& Joint Surg. 1964; 46(3):404-424.

3. Sarmiento, Augusto, Cooper SJ, Sinclair FW. Forearm fractures. J Bone\& Joint Surg. 1975:57-A (3):297-3.

4. Richards RR. Fractures of the shafts of the radius and ulna. In. Bucholz RW, Heckman JD, editors. Rockwood and Green's fractures in adults. 5th ed. Philadelphia, USA: Lippincott Williams and Wilkins, 2001, 869-917.

5. Dodge Herbert S, Gerald W. Cady: Treatment of fractures of the radius and ulna with compression plates. J Bone Joint Surg. 1972: 54-A(6):1167-1176

6. Chapman MW, Gordon JE, Zissimos AO. Compressionplate fixation of acute fractures of the diaphysis of the radius and ulna. J. Bone Joint Surg. Am. 1989; 71:159169.

7. Moed BR, Kellam JF, Foster RJ, Tile M, Hansen ST. Immediate internal fixation of open fractures of the diaphysis of the forearm. J. Bone Joint Surg. Am. 1986; 68:1008-1017.
8. Hidaka S, Gustillo RB. Refracture of bones of forearm after plate removal. Bone Joint Surg Am. 1984; 66:12411243.

9. William Larsen J. Human Embryology -1 edition, 281286.

10. Smith H, Sage FP. Medullary fixation of forearm fractures. J. Bone Joint Surg. Am. 1957; 39:91-188.

11. Hoppenfeld. The forearm. Chapter-4 in Surgical exposures in orthopedics, 2nd Edn, Philadelphia; Lippincott Raven Publishers, 1999, 117-133.

12. Sarmiento, Augusto, Cooper SJ, Sinclair FW. Forearm fractures. J Bone \& Joint Surg. 1975:57-A(3):297-30.

13. Talwalkar K. Treatment of simple fractures of radius and ulna with internal fixation without external support. Singapore Medical Journal. 1967; 8:3.

13. Grace JG, Eversmann WWJR. Forearm fractures treated by rigid fixation with early motion. J Bone \&. Joint surg. 1980; 68-A, 43-438.

14. Bagby GW. Bone J. Joint Surg Am. Compression bone plating: historical considerations. 1977; 59:625-631. 